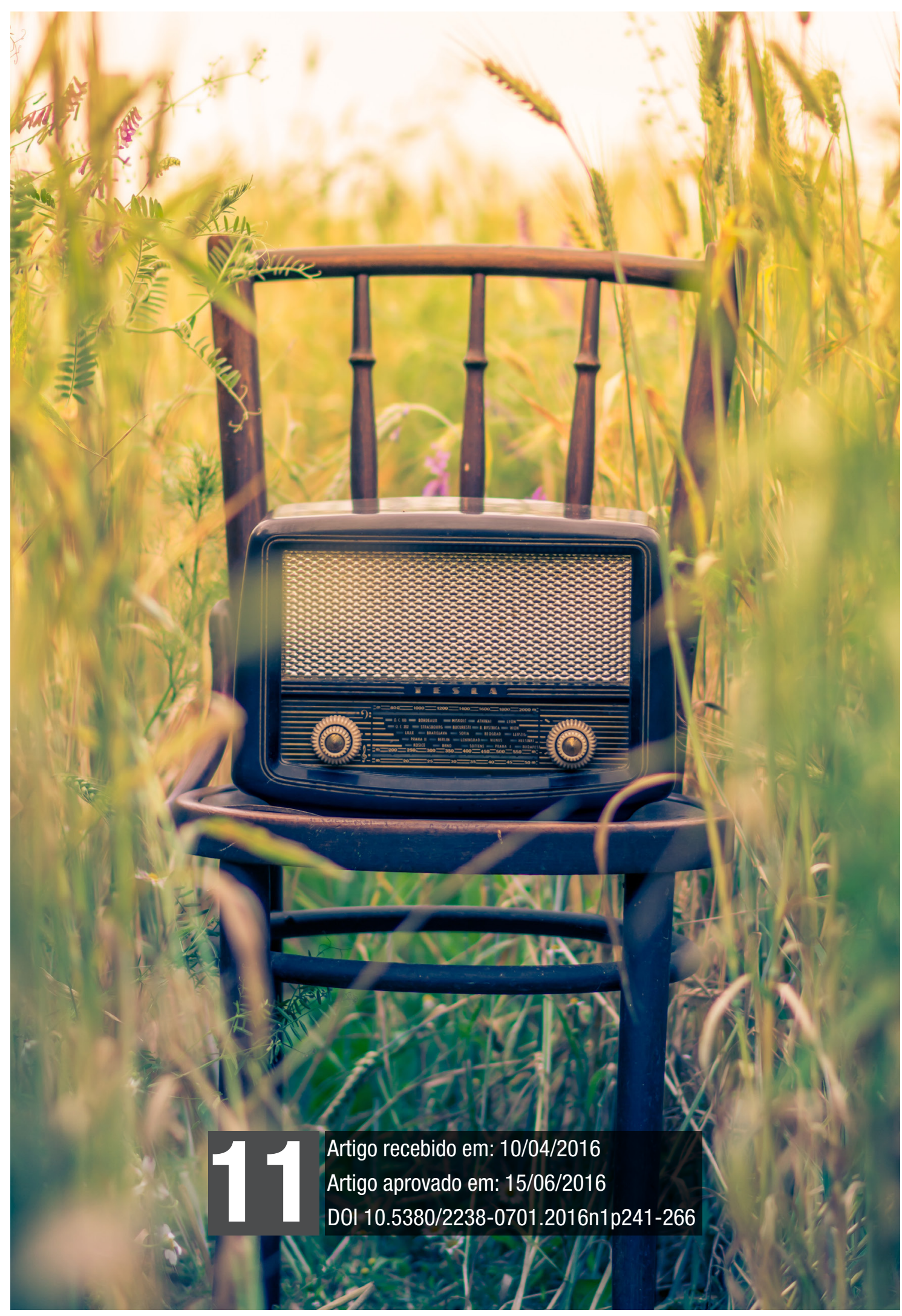


Coronéis midiáticos. Concentração midiática.

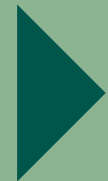




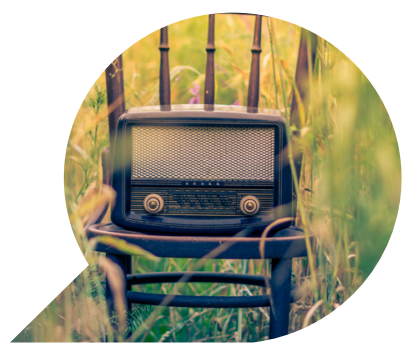

\section{Coronelismo eletrônico: a concentração do poder midiático nacional e no Paraná}

Electronic coronelism: the concentration of national media power and Paraná

Coronelismo electrónico: concentración del poder mediático nacional y Paraná

GERALDO PIERONI *

ANDRÉ KRON MARQUES ZAPANI **

Resumo: Este artigo objetiva analisar o campo midiático brasileiro, particularmente o espaço paranaense, e suas práticas dominadas pelo clientelismo e concentração do poder. Trataremos das origens institucionais das relações de poder na esfera social e midiática e do surgimento do protagonista indissociável deste campo - o "coronel eletrônico" - bem como da sua importância no contexto da proposta deste artigo (concentração do poder da mídia). Partindo desta premissa será estudada a convergência conflituosa e tendência do poder político e meios de comunicação sociais, tomando por base pesquisas quantitativas que evidenciam a ilegal direção/posse de empresas radiofônicas

\footnotetext{
* Doutor em História pela Université de Paris IV - Paris-Sorbonne. Prof. Dr. do Programa de PósGraduação Stricto Sensu em Comunicação e Linguagem da Universidade Tuiuti do Paraná.

** Doutorando do Programa de Pós-Graduação Stricto Sensu em Comunicação e Linguagem da Universidade Tuiuti do Paraná.
} 
em nome de parlamentares federais e estaduais. Observaremos, também, outra característica controversa presente no campo comunicacional nacional - a propriedade cruzada - que é responsável pela retração da globalização das mídias, pelo soterramento reiterado da informação e relevante fomentadora desta aglutinação dos órgãos de comunicação.

Palavras-chave: Coronéis midiáticos; Concentração midiática; Propriedade cruzada.

Abstract: This article aims to analyze the Brazilian media field, particularly Paranaense space, and practices dominated by clientelism and concentration of power. We will address the institutional sources of power relations in social and media sphere and the emergence of the inseparable protagonist of this field - the "electronic Colonel" - as well as its importance in the context of the purpose of this article (concentration of media power). On this assumption we will study the conflict and convergence tendency of political power and social media, based on quantitative research that show illegal direction / ownership of radio companies on behalf of federal and state lawmakers. We observe also another feature present in the controversial national communication field - cross-ownership - which is responsible for the contraction of globalization of the media, at the continued burial of relevant information and a sponsor of this assemblage of media outlets.

Key words: Colonels media; Media concentration; Cross-ownership.

Resumen: El objetivo de este artículo es analizar el campo mediático brasilero, particularmente el espacio paranaense, y sus prácticas dominadas por el clientelismo y la concentración del poder. Trataremos los orígenes institucionales de las relaciones del poder en la esfera social y mediática y del surgimiento del protagonismo inseparable de este campo - el "coronel electrónico" - bien como de su importancia en el contexto de la propuesta de este articulo (concentración del poder de la media). Partiendo de esta premisa será estudiada la convergencia conflictiva y la tendencia del poder político y los medios de comunicación so- 
cial, tomando por base las investigaciones cuantitativas que evidencian la ilegal dirección/posesión de empresas radiofónicas en nombre de parlamentarios federales y estaduales. Observaremos, también, otra característica, la controversia presente en el campo comunicacional nacional - la propiedad cruzada - que es responsable por la retracción de la globalización de las medias, por el soterramiento reiterado de la información $y$ el relevante fomento de esta concentración de los órganos de comunicación.

Palabras claves: Coroneles mediáticos; Concentración mediática; Propiedad cruzada. 


\section{O coronel e seus castelos}

O processo de formação dos impérios midiáticos brasileiros atuais remete a uma contextualização temporal à época colonial (1534-1548). Periodização referente ao estabelecimento das capitanias hereditárias alicerçadas nas relações de apadrinhamento, de poder clientelístico e de nepotismo cuja reminiscência permaneceu nos campos político e midiático contemporâneos. Essa revisitação na trajetória histórica se faz necessária à compreensão das consolidações e alianças entre o poder político de outrora e o Executivo contemporâneo, sem, contudo, querer comprovar que esta fase histórica foi a origem do conceito de coronelismo eletrônico, a ser discutido neste artigo. A referência à colonização portuguesa nos aponta que as relações de poder existentes no âmbito dos notórios capitães donatários e, posteriormente, do mandonismo regional do coronelismo, apresentam características de clientelismo que perduram até os nossos dias nas várias instâncias institucionais incluindo os empresários do ramo da comunicação do século XX e XXI.

Os senhores dessas capitanias foram oriundos da pequena nobreza portuguesa e foram escolhidos pelo poder financeiro, pela familiaridade, pela representatividade social e pela proximidade com a nobreza real. Possuíam o direito de usufruir das propriedades, mas não as tinham como donos (processo semelhante às concessões radiofôni$\left.\operatorname{cas}^{1}\right)$. Essas relações de poder político vinculado às conveniências mútuas e a interesses conjuntos transpassam os idos iniciais do Brasil Colônia e se tornam moldáveis ao transcurso temporal nacional. $\mathrm{O}$ objeto de discussão e de disputa nessa relação sociopolítica entre os detentores "de fala" é perene, mas de formatação reiterada e amorfa, mas sempre seguindo os padrões do sistema econômico de sua época.

As relações de poder existentes no patrimonialismo foram analisadas por Raymundo Faoro, na obra intitulada "Os donos do poder: formação do patronato político brasileiro". O autor justifica a trajetória do Brasil de hoje como consequência da política adotada por Portugal na época de sua colonização. O Condado Portucalense se

\footnotetext{
${ }^{1}$ Segundo o Ministério das Comunicações, serviços radiofônicos são classificados como transmissão de sons (radiodifusão de sons) e de sons e imagens (televisão), a serem direta e livremente usufruídas pelo público em geral. No Brasil, esses serviços têm, legalmente, finalidade educativa e cultural e são considerados de interesse nacional.
} 
tornou Reino de Portugal de maneira ímpar pelo fato de o rei ser, ao mesmo tempo, governante e senhor feudal. O Monarca administrava o Reino e por possuir o atributo de senhor absoluto do patrimônio real, ele tomava as decisões com base em critérios pessoais, subjetivos, um verdadeiro proprietário das terras nas quais ele governava. Desta forma, o bem público estava associado aos bens do governante como indivíduo e, portanto, o rei era o senhor legítimo do poder e todos estavam submetidos à sua vontade. Com a chegada dos primeiros colonizadores portugueses na Terra Brasilis, foram gradativamente estabelecidas as mesmas instituições políticas da Metrópole. O Brasil deveria ser outro Portugal, reproduzindo a mesma política institucional adotada em terras lusas. Também a América portuguesa foi nutrida pelos funcionários-súditos, nítida decisão burocrática que se utilizava dos benefícios concedidos pelo governante (Faoro, 1958).

Historiadores, sociólogos ${ }^{2}$ e cientistas políticos já se debruçaram sobre estas condições das dependências mútuas e, portanto, não nos alongaremos nestas análises visto que nosso objetivo é buscar nestes conceitos a permanência dos comportamentos contaminados do exercício político dos donos do poder.

Os estudos de Schwartzman, por exemplo, explanam detalhadamente as relações entre cooptação e a manutenção do poder centralizado apontando a necessidade de substituição do Estado patrimonialista por outro modelo de ordenamento.

Ao cooptar, o centro se enfraquece, mas, ao mesmo tempo tira a autonomia dos cooptados, que de constituintes se transformam em clientes. A consequência é a formação de um sistema político pesado, irracional em suas decisões, que se torna presa de uma teia cada vez maior e mais complexa de compromissos e acomodações, até o ponto de ruptura. O Estado patrimonialista, clientelista, acomodador, é visto como uma reminiscência do passado, do tradicional, do conservador, e a necessidade de sua substituição por um novo tipo de ordenamento jurídico-político se impõe (Schwartzman, 1982).

Essas particularidades apontadas acima perpassaram pela cultura política brasileira produzindo compadrio, laços mantidos pela

\footnotetext{
${ }^{2}$ Segundo WEBER (1968), primeiramente, o patrimonialismo é uma categoria referente a três tipos puros de dominação presentes na sociedade e em sua história: dominação racional-legal, dominação carismática e dominação tradicional, esta última representando uma legitimidade baseada no comando "espontâneo" introduzido culturalmente por regras pré-estabelecidas no costume arraigado e sendo subdividida em patrimonialista ou feudal.
} 
relação desigual e troca de favores e benefícios e laços afetivos de dependência. A partir dessa relação de poder dominada pela submissão e permutas de favores, surge a afinidade de compadrio, haja vista que muitos dependentes davam seus filhos para serem apadrinhados pelo senhor das terras.

Novas configurações destas relações patrimoniais ganham maior espaço com os mandatários locais. O "coronelismo", grosso modo, foi uma prática definida para designar os opulentos fazendeiros, os comerciantes, os industriais mais abastados e os integrantes da Guarda Nacional que detinham o poder regional e a hegemonia social, econômica e política sobre os miseráveis habitantes das regiões interioranas do país. Posteriormente, os sertanejos denominavam "coronéis" todos os homens que tiveram grande expressão na política municipal, a partir do final do século XIX, adentrando-se pela República Velha (1889-1930).

No âmbito nacional, o governo de Getúlio Vargas se caracterizou pela centralidade do poder no Executivo, na União e consequente debilidade do poder regional, lócus de atuação dos coronéis. Outro fator que corrobora o fim desta figura social foi a inclusão do voto secreto, na Constituição de 1934, excluindo as prerrogativas do voto de cabresto nos currais eleitoreiros, bem como a inexistência de votação direta nos governos militares, em período posterior.

O conceito "coronelismo", segundo Santos (2008a), é controverso quanto a sua finitude na história social. Para Leal (1997) e Carvalho (2005), este fenômeno teve seu fim por ocasião da implantação do Estado Novo, em 1937, e consequente queda do governador do Rio Grande do Sul, Flores da Cunha3 ${ }^{3}$ Já Barbosa Lima Sobrinho, em prefácio de Leal (op.cit.), acredita que as práticas patrimoniais clientelistas dos mandatários locais sobrevivem até hoje, fruto da transformação do coronel em "doutor", da fazenda em fábrica e dos assessores em técnicos. O coronel continua sendo coronel, no entanto com outra configuração político-econômica. Esta opinião é também compartilhada por Santos \& Capparelli (2005) e Suzy Santos (2008a; 2008 b). O coronelismo se adaptou ao novo formato político nacional, à manutenção da corrupção estatal e à situação de abandono de várias cidades interioranas.

\footnotetext{
${ }^{3}$ Ver Bellintani (2002) e Cortés (2007) para aprofundamento histórico e biográfico de Flores da Cunha.
} 
Corrobora-se com este posicionamento conceitual a ideia que, além de "no interior do Nordeste, continua sem mudança significativa, mesmo com todas as transformações políticas e socioeconômicas ocorridas no cenário brasileiro, da década de 30 para cá [...] o coronelismo continua sem modificações em sua essência" (SANTOS, 2008b).

Os coronéis eram grandes latifundiários e empregadores de massas servis que detinham relações de dependência. Situações idênticas tinham os poderes municipais com o Estado e este com a Federação, haja vista que dependiam do voto para o prosseguimento de seus mandatos e, indiretamente, dos proprietários de terras que, na base da coerção física e psicológica (voto de cabresto), retroalimentavam a estrutura política.

Em troca os coronéis recebiam favorecimentos: empregos públicos estaduais para distribuição, verbas extras, exclusividade e centralização na administração municipal. "No seu município [do coronel José Bezerra] dominou por muito tempo o regime do Estado sou eu. O município era êle. A lei era êle. O juiz, o delegado, o padre, era ele" (CARONE, 1971, p. 87).

Desta forma, interesses privados se imbricavam na seara pública, tornando os limites demarcatórios em processos subjetivos de fluxos recíprocos de favorecimento.

Para Carvalho, a definição de clientelismo é confundida com o de coronelismo. Para ele este foi um conceito muito usado, sobretudo por autores estrangeiros escrevendo sobre o Brasil, desde o trabalho pioneiro de Benno Galjart (1964; 1965), o conceito de clientelismo foi sempre empregado de maneira frouxa. De modo geral, indica um tipo de relação entre atores políticos que envolvem concessão de benefícios públicos, na forma de empregos, benefícios fiscais, isenções, em troca de apoio político, sobretudo na forma de voto (...) Clientelismo seria um atributo variável de sistemas políticos macro e podem conter maior ou menor dose de clientelismo nas relações entre atores políticos. Não há dúvida de que o coronelismo, no sentido sistêmico aqui proposto, envolve relações de troca de natureza clientelística. Mas, de novo, ele não pode ser identificado ao clientelismo, que é um fenômeno muito mais amplo. Clientelismo assemelha-se, na amplitude de seu uso, ao conceito de mandonismo. Ele é o mandonismo visto do ponto de vista bilateral. Seu conteúdo também varia ao longo do tempo, de acordo com os recursos controlados pelos atores políticos, em nosso caso pelos mandões e pelo governo (Carvalho, 2005). 


\section{A indissociável relação entre parlamentares e coronéis}

Essa conivência política marcada por interesses pessoais, no sistema coronelista, caracteriza o atual sistema brasileiro de comunicações que faz do apadrinhamento, do clientelismo e do devir econômico predicado de destaque e de existência.

A evolução conceitual e histórica dessa relação sofre extensões interpretativas, a ponto de Santos \& Capparelli (op. cit.) reinterpretarem a obra "Coronelismo, enxada e voto", de Victor Leal Nunes (1997) sob a ótica "Coronelismo, radiodifusão e voto".

Os coronéis de outrora passam a integrar a política midiática do século XXI, fruto principalmente do surgimento da televisão e do rádio, da expansão do mercado impresso e dos espaços digitais, meios eficazes de difusão ideológica e, principalmente, de expansão da hegemonia política e do poder simbólico que não se limita mais exclusivamente em seus currais eleitoreiros locais, mas em regiões longínquas, quiçá nas de seus adversários.

Os mandões modernos buscam se aferrar cada vez mais à radiodifusão e visam adquirir outras plataformas de comunicação a fim de concentrar a informação bem como qualificar sua programação com intuito de reter suas audiências, manter suas rendas publicitárias e difundir sua ideologia política.

A moeda de troca desse sistema comunicacional é o voto do eleitorado rural vinculado aos coronéis via motivação midiática em favor do político aliado, que, em contrapartida, facilita ao coronel eletrônico a outorga e, futuramente, a renovação das concessões do serviço de radiodifusão, além de apoio publicitário no orçamento da emissora "cedida". O "coronelismo eletrônico" torna-se presente, é a manutenção das elites políticas tradicionais, é a aliança entre o poder privado e os detentores das concessões radiofônicas, além de conceitualmente ser:

O sistema organizacional da recente estrutura brasileira de comunicações, baseado no compromisso recíproco entre poder nacional e poder local, configurando uma complexa rede de influências entre o poder público e o poder privado dos chefes locais, proprietários dos meios de comunicação (SANTOS, 2008a, p. 2). 
Abaixo, no gráfico 1, pode-se verificar quantitativamente a evidente relação entre os coronéis e a radiodifusão:

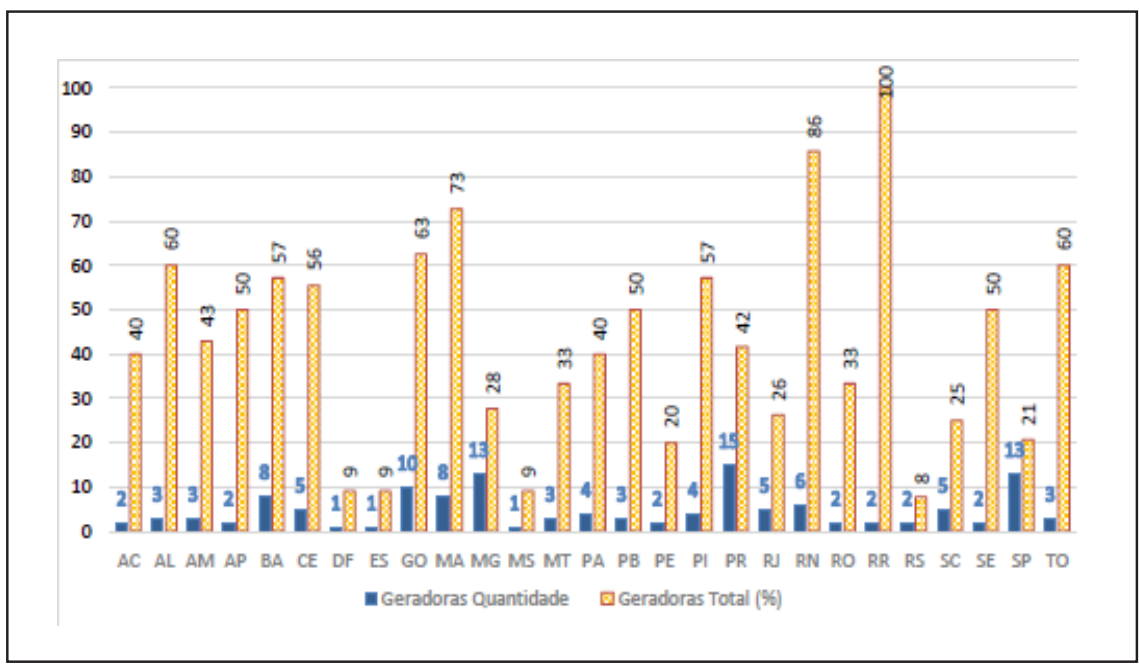

Gráfico 1: Outorgas de televisão controladas por políticos, Santos \& Capparelli (op. cit., p.95)

Nota-se, no gráfico 1, que 33,6\% das geradoras de televisão encontram-se polarizadas nas mãos de políticos dos poderes executivo e legislativo ${ }^{4}$, grande evidência que os campos midiáticos e políticos caminham juntos.

Em levantamento quantitativo díspar, elaborado por James Görgen $^{5}$ (2015), gráfico 2, que teve como objeto de análise figuras políticas sócias ou diretores de veículos de comunicação, o resultado corroborou com a análise anterior:

\footnotetext{
${ }^{4} \mathrm{~A}$ metodologia utilizada no gráfico 1 , segundo os autores, foi “uma busca genérica na internet e em arquivos de jornais e revistas do país".

${ }^{5}$ Segundo a metodologia de James Görgen, "a propriedade de veículos de comunicação por parte de políticos com mandato pode ser maior que a apresentada. Optou-se por listar somente o controle direto ou a participação societária exercida por essas pessoas. Veículos exclusivamente em nome de familiares ou outros sócios não foram registrados. Da mesma forma, não foram computadas as propriedades de vereadores." O levantamento cruzou dados da Agência Nacional de Telecomunicações com a lista de prefeitos, governadores, deputados e senadores de todo o país para mapear quais deles são proprietários de veículo de comunicação
} 


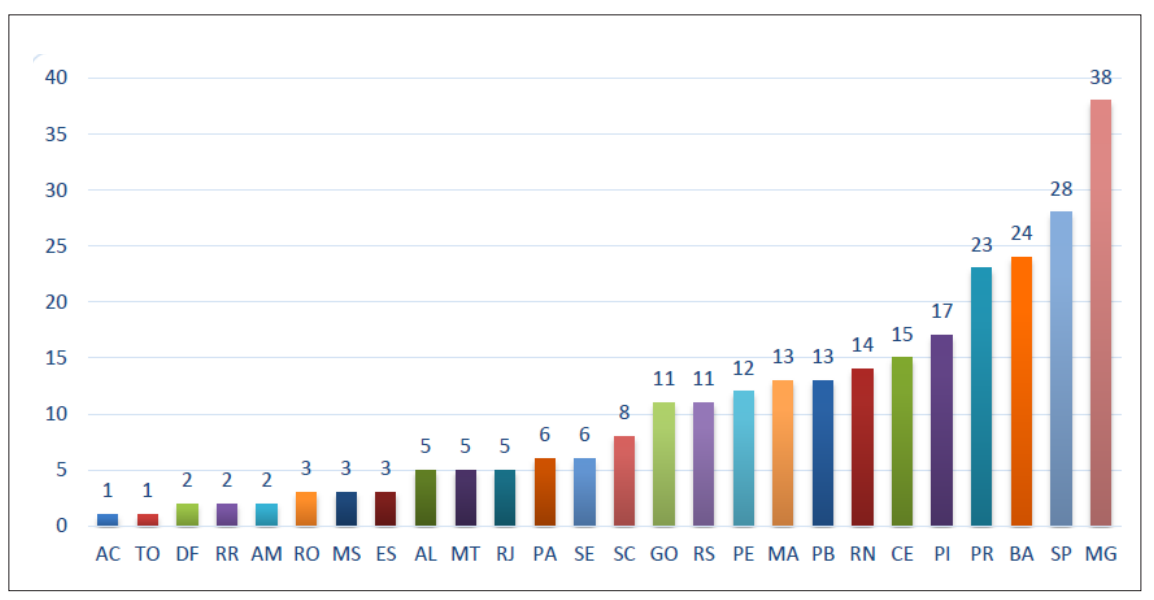

Gráfico 2: Número de políticos sócios ou diretores de veículos de comunicação por estado, Görgen (op. cit.)

O poderio governamental e simbólico que políticos passaram a adquirir face ao controle de mídias massivas é notório - 271 políticos são sócios ou diretores de 324 veículos de comunicação no Brasil. No total desses veículos: 7,38\% pertencem a senadores, $0,37 \%$ a governadores, $54,24 \%$ a prefeitos, $17,71 \%$ a deputados federais e $20,3 \%$ a deputados estaduais ${ }^{6}$.

No entanto, segundo o artigo 54 da Constituição Federal de 1998, deputados e senadores não poderão:

I - desde a expedição do diploma:

a) firmar ou manter contrato com pessoa jurídica de direito público, autarquia, empresa pública, sociedade de economia mista ou empresa concessionária de serviço público, salvo quando o contrato obedecer a cláusulas uniformes.

b) aceitar ou exercer cargo, função ou emprego remunerado, inclusive os de que sejam demissíveis ad nutum, nas entidades constantes da alínea anterior (BRASIL, 1988, Art. $7^{\circ}$ ).

Esta prática ilegal corriqueira e quase que institucionalizada é confirmada pelo levantamento feito por DIAP (2014) constatando que a bancada dos meios de comunicação no Congresso Nacional, que inclui parlamentares em todos os partidos, embora tenha perdido em qualidade para a legislatura do mandato 2015-2019, continua

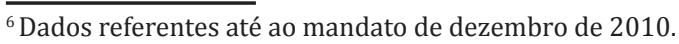


contando com algo em torno de 60 parlamentares entre os concessionários de rádio ou de televisão, mesmo sem a presença na próxima legislatura, por exemplo, de expoentes como José Sarney (PMDB-AP), Henrique Eduardo Alves (PMDB-RN) e Inocêncio Oliveira (PR-PE).

Apesar das perdas mencionadas, a bancada contará com a deputada Elcione Barbalho (PMDB-PA), reeleita; com Sarney Filho (PV$\mathrm{MA}$ ), reeleito; com Miro Teixeira (PROS), reeleito; com Arolde Oliveira (PSD-RJ), reeleito; com o senador Fernando Collor (PTB-AL), reeleito; com os senadores do PMDB Edison Lobão, Romero Jucá e Jader Barbalho, que tem mandato até 2019, além de contar com o novo senador Tasso Jereissati (PSDB-CE) e o novo deputado Ricardo Barros (PP-PR).

Levantamento feito, após a confirmação do resultado das eleições de 2014, pelo jornal a Folha de São Paulo, aponta que "ao menos 55 concessões pelo país pertencem a políticos que vão tomar posse em 2015 que juntas, as rádios e televisões somam patrimônio de R\$ 8,3 milhões" (BACHTÖLD, 2014).

Os números destes recenseamentos são distintos, tendo em vista a metodologia de apuração utilizada, mas principalmente pela dificuldade de se descobrir quem são os reais proprietários destes veículos, pois diversos estão em nome de terceiros ou familiares.

A precisão nos números destas pesquisas é um quesito de menor importância se comparada com essa quase institucionalizada ilegalidade que é uma característica consolidada na política midiática brasileira e que sobrevive devido à pouca divulgação pelos veículos de comunicação à sociedade civil, à apatia das audiências, bem como às alianças dos coronéis com a grande mídia comercial e às reinterpretações ordinárias e tendenciosas dos políticos sobre o assunto.

Corroborando essa parcialidade, o deputado Arolde de Oliveira (PSD-RJ) disse que "impedir sócios de emissoras de se candidatar seria discriminação. Se até analfabeto pode ser candidato, eu não posso por ter uma emissora?", bem como a declaração do deputado Gonzaga Patriota (PSB-PE), sócio em duas rádios, "que a internet mudou o cenário que esses meios costumavam ter. Hoje os meios de comunicação são democráticos" (BACHTÖLD, op. cit.).

O cenário político-midiático paranaense, no tocante à posse parlamentar de veículos de comunicação radiofônicos, não é diferente do contexto nacional. Referido óbice foi constatado, mas em menor 
proporção que na esfera nacional, em levantamento feito por este autor tomando por base o executivo e os deputados estaduais e federais paranaenses eleitos para o mandato 2015-2019 que são proprietários (tabela 1) ou têm vínculos familiares diretos com os sócios (tabela 2):

\begin{tabular}{r|c|c|c|c}
\hline \multicolumn{1}{c|}{ Nome } & Mandato & Partido & Emissora & Cidade \\
\hline Dilceu João Sperafico & Dep. Federal & PP & Rádio Difusora AM & Mal Candido Rondon \\
\hline Ricardo Barros & Dep. Federal & PP & Rádio Ingá AM & Maringá \\
\hline Luiz Carlos Martins & Dep. Estadual & PDT & Rádio Banda B & Curitiba \\
\hline Luiz Claudio Romanelli & Dep. Estadual & PMDB & Rádio Banda B & Curitiba \\
\hline Cantora Mara Lima & Dep. Estadual & PSDB & Rádio Louvor Eterno & Mandaguari \\
\hline Cida Borgheti & $\begin{array}{c}\text { Vice- } \\
\text { governadora }\end{array}$ & PROS & Rádio Difusora AM & Maringá \\
\hline
\end{tabular}

Tabela 1: Parlamentares paranaenses proprietários de emissoras.

\begin{tabular}{|c|c|c|c|c|}
\hline Sandro Alex ${ }^{\prime}$ & Dep. Federal & PPS & Rádio Central & Ponta Grossa \\
\hline Bernardo Carli $^{8}$ & Dep. Estadual & PSDB & Rádio Guaicará & Guarapuava \\
\hline \multirow{8}{*}{ Ratinho Júnior $^{9}$} & \multirow{8}{*}{ Dep. Estadual } & \multirow{8}{*}{ PSC } & TV Guará & Ponta Grossa \\
\hline & & & TV Tibagi & Apucarana \\
\hline & & & TV e Rádio Iguaçu & Curitiba \\
\hline & & & TV Naipi & Foz do Iguaçu \\
\hline & & & TV Cidade & Londrina \\
\hline & & & $\begin{array}{l}\text { Rádio Menina do } \\
\text { Paraná }\end{array}$ & Campo Largo \\
\hline & & & Rádio Eldorado & São José dos Pinhais \\
\hline & & & Rádio Náutica FM & Maringá \\
\hline Maria Victória $^{10}$ & Dep. Estadual & $\mathrm{PP}$ & Rádio Jornal AM & Maringá \\
\hline Alexandre Curi ${ }^{11}$ & Dep. Estadual & PMDB & Rádio Poema & Pitanga \\
\hline
\end{tabular}

Tabela 2: Parlamentares paranaenses parentes de proprietários de emissoras, Ministério das Comunicações (2015).

\footnotetext{
${ }^{7}$ Filho Nilson de Oliveira, proprietário também da Rádio Mundi FM, na mesma cidade.

${ }^{8}$ Irmão do ex-deputado Luiz Fernando Carli Filho, proprietário da Rádio Guaicará.

${ }^{9}$ Filho do proprietário da Rede Massa, Carlos Massa - o "Ratinho".

${ }^{10}$ Filha do Dep. Federal Ricardo Barros e da Vice-governadora do Paraná, Cida Borgheti.

${ }^{11}$ Filho do ex-deputado Aníbal Khury Jr, proprietário da Rádio Poema.
} 
A Constituição de 1988 determinou como novidades atribuições do Congresso Nacional, que até então cabia exclusivamente ao Executivo, a apreciação dos atos de outorga e renovação de concessão, permissão e autorização para o serviço de radiodifusão sonora e de sons e imagens, fato que ocasionou um grande incremento nos trabalhos da CCTCI. Além da expansão da radiodifusão, especialmente com a instituição da radiodifusão comunitária, temas como a privatização das telecomunicações, a utilização de software livre, a inclusão digital e a criação das agências reguladoras fazem parte dos principais debates e deliberações da comissão.

Essa comissão, uma das 20 permanentes da Câmara dos Deputados, que é constituída por 42 deputados titulares e igual número de suplentes, atua como órgão técnico da Casa, apoiada por consultores legislativos e servidores administrativos. Curiosamente, diversos parlamentares federais sócios ou associados de concessões de radiodifusão compõem a CCTCI e outorgam e renovam suas próprias concessões ou facilitam as de seus familiares, apadrinhados ou "laranjas". Podem ser inclusos nesta confluência de interesses: Sandro Alex, vice-presidente desta comissão; Antônio Bulhões, suplente e deputado recordista de concessões radiofônicas no país (7 emissoras); Ratinho Júnior, ex-presidente da subcomissão permanente de radiodifusão e integrante titular até 2015.

Regredindo, em uma década, objetivando a consolidar a constância desta prática de autobenefício, que estabiliza a perpetuação do velho coronelismo e da adaptação para o coronelismo eletrônico, Lima (2006) demonstra que, em 2003, 15 dos 36 deputados membros da CCTCI eram concessionários de emissoras de rádio ou TV. Em 2004, a proporção aumentou para 15 deputados proprietários entre 29 integrantes.

\section{Propriedades cruzadas}

Outro predicado neste contexto acondicionado do campo midiático brasileiro é a propriedade cruzada que, segundo definição de Lima:

Trata-se da propriedade pelo mesmo grupo, de diferentes tipos de mídias do setor da comunicação. Por exemplo: TV aberta, TV por assinatura, rádio, revistas, jornais, e, mais recentemente, telefonia (fixa, celular e móvel, via satélite), provedores de internet, transmissão de dados, paging etc. (2012, p. 105). 
Esta prática encontra seu amparo legal no decreto-lei no 236, que complementa o CBT, nas seguintes condições:

\begin{tabular}{|l|l|l|l|l|}
\hline & \multicolumn{5}{c}{ Limites de Propriedade: Rádio } \\
\hline & $\begin{array}{l}\text { Onda Media } \\
\text { (OM) }\end{array}$ & $\begin{array}{l}\text { Frequencia } \\
\text { Modulada } \\
\text { (FM) }\end{array}$ & Onda Tropical & Onda Curta \\
\hline Local & 04 & 06 & - & - \\
\hline Regional & 03 & - & $\begin{array}{l}03 \text { (no máximo } \\
02 \text { por UF) }\end{array}$ & - \\
\hline Nacional & 02 & - & - & 02 \\
\hline
\end{tabular}

\section{Limites de Propriedade: Televisão}

10 emissoras no território nacional, sendo 05 em VHF; 02 por Estado; e apenas 1 por localidade.

Tabela 3: Limite de concessão/permissão para executar serviço de radiodifusão por cada entidade, Brasil (1967, Art. 12).

No entanto, verifica-se que o quadro de propriedades cruzadas no país não coaduna com o previsto em legislação, a ponto do então ministro das Comunicações, Paulo Bernardo, em 2011, expor sua posição contrária a esta prática corriqueira, mesmo ciente das dificuldades em extingui-las: "o que nós queremos é o seguinte: é fazer limitação mais definida e mais clara sobre a concentração da mídia na mão de poucos" (LIMA, 2011b).

Todavia, esta intenção do ex-ministro à época parou por aí mesmo - na intenção. Recentemente, segmentos da sociedade midiática vêm tentando desconstruir o conceito de propriedade cruzada ao tentar equipará-la à convergência midiática, argumentando que os veículos de comunicação hoje "só têm num só portal seus noticiários de jornal, rádio e televisão, na maioria dos casos funcionando num mesmo ambiente físico e virtual, com aproveitamento de toda produção de conteúdo" (LIMA, 2011c).

O Grupo RBS7, maior conglomerado midiático do sul do país,

\footnotetext{
${ }^{12}$ Concentração midiática da família Sirotsky. Possui 8 emissoras de rádio, 20 emissoras de TV aberta, 8 jornais e 1 portal de notícia nos estados de SC e RS. No entanto, foi anunciado, em março de 2016, acordo entre os acionistas da RBS e os empresários Lírio Parisotto e Carlos Sanchez, do Grupo NC, juntamente com outros investidores, para a compra das operações de televisão, rádio e jornal que atuam sob a marca RBS em Santa Catarina. A conclusão do negócio ainda está sujeita à condição suspensiva de aprovação prévia do Conselho Administrativo de Defesa Econômica e dos demais órgãos regulatórios do setor, bem como ao cumprimento de determinadas condições precedentes usuais para estes tipos de transações.
} 
corrobora com esta reinterpretação:

Felizmente, o governo Dilma começa a emitir sinais de que está mudando o rumo do debate sobre o novo marco regulatório do setor de comunicações. Ao que tudo indica, sairão de cena velhos ranços ideológicos, entre os quais a campanha pelo veto à propriedade cruzada de veículos de informação e a obsessão pelo controle social da mídia, e entrarão em discussão temas objetivos como a própria liberdade de imprensa, a qualidade dos conteúdos e o cumprimento rigoroso dos preceitos constitucionais. [...]. É bom que assim seja, até mesmo para que o país não perca tempo e energia com impasses ultrapassados, como o do veto à propriedade cruzada. [grifo nosso] A própria tecnologia se encarregou de derrubar este conceito, pois a convergência das mídias fez com que informações, dados e imagens passassem a trafegar simultaneamente em todas as plataformas. (LIMA, 2011a)

Contrapondo a esta argumentação da RBS, o fato de haver convergência das mídias não exclui a situação de que as mídias de massa continuem produzindo conteúdos para plataformas singulares, com audiências únicas e narrativas próprias.

A concentração cruzada é etapa fundamental para a formação dos monopólios e oligopólios regionais. Esta centralização de meios em restritos grupos restringe a diversidade e a pluralidade de vozes, nivela práticas jornalísticas, causa um soterramento monofônico da notícia e restringe a liberdade democrática.

Paradoxalmente, os conglomerados midiáticos, representados pela Associação Brasileira de Emissoras de Rádio e TV (ABERT), que tem entre seus objetivos defender a liberdade de expressão (ABERT, 2015), são os primeiros a subverterem a legislação vigente, partindo do princípio de uma reinterpretação, impedindo a globalização da informação, do conhecimento, da ampliação dos mercados e da polifonia.

Levantamentos feitos por Querino (2001) e Pieranti (2015) demonstram a relevância e a importância dada por outros países no tocante a propriedade cruzada, principalmente quanto à sua limitação e à possibilidade de não se reduzir o número de vozes atuantes: 


\begin{tabular}{|c|c|}
\hline País & Peculiaridades da propriedade cruzada \\
\hline EUA & $\begin{array}{l}\text { - Um mesmo grupo não pode deter outorgas de emissoras } \\
\text { de TV que cheguem potencialmente a mais de } 39 \% \text { dos } \\
\text { domicílios. } \\
\text { A propriedade cruzada é permitida no caso de emissoras } \\
\text { locais, porém seu limite varia em função do total de } \\
\text { emissoras independentes existentes no mercado local. } \\
\text { - Um mesmo grupo não pode controlar } 1 \text { jornal diário e } \\
1 \text { emissora de radiodifusão de alta potência que cubram } \\
\text { o mesmo município. }\end{array}$ \\
\hline ALEMANHA & $\begin{array}{l}\text { - Não há restrição. Limite definido pelo índice de } \\
\text { audiência das estações proprietárias (até } 30 \% \text { ). }\end{array}$ \\
\hline FRANÇA & $\begin{array}{l}\text { - Uma pessoa somente pode ter } 1 \text { rede TV com audiência } \\
\text { de } 4 \text { milhões de pessoas; ou } \\
\text { - Uma pessoa somente pode ter serviço de radiofusão } \\
\text { sonora com audiência de } 30 \text { milhões de pessoas; ou } \\
\text { - Uma pessoa pode ter uma TV a cabo com audiência de } \\
\text { até } 6 \text { milhões de pessoas. }\end{array}$ \\
\hline ITÁLIA & $\begin{array}{l}\text { - Uma pessoa pode ter no máximo } 3 \text { concessões de TV } \\
\text { nacionais. Para estações locais, é permitida } 3 \text { frequências } \\
\text { diferentes. }\end{array}$ \\
\hline $\begin{array}{l}\text { REINO } \\
\text { UNIDO }\end{array}$ & $\begin{array}{l}\text { - Empresa controladora de um jornal nacional com mais } \\
\text { de } 20 \% \text { do mercado não pode deter uma licença para } \\
\text { retransmitir Canal 3, nem deter participação superior a } \\
20 \% \text { em outra outorga destinado a retransmiti-lo. } \\
\text { - Não há limites para total de emissoras de outorgas para } \\
\text { emissoras de rádio local controladas por um mesmo } \\
\text { grupo. } \\
\text { Autorizada a propriedade cruzada no nível local, } \\
\text { desde que uma mesma entidade não disponha } \\
\text { simultaneamente de } 1 \text { jornal local com mais de } 50 \% \text { do } \\
\text { mercado; rádio local e TV local que transmita o Canal } 3 .\end{array}$ \\
\hline ARGENTINA & $\begin{array}{l}\text { - Limite máximo de } 24 \text { licenças. Na mesma localidade, } \\
\text { apenas } 1 \text { licença radiofônica. }\end{array}$ \\
\hline PORTUGAL & $\begin{array}{l}\text { - Limite máximo de concessões por pessoa é de } 5 \text {. Em uma } \\
\text { mesma localidade, não são autorizadas participações } \\
\text { superiores a } 25 \% \text { de outro capital social. }\end{array}$ \\
\hline
\end{tabular}

Tabela 4: Levantamento da propriedade cruzada em outros países, Querino (2001) e Pieranti (op.cit.) 
Entretanto, a limitação imposta pelas nações internacionais a seus mercados radiofônicos comerciais visando restringir as propriedades cruzadas não corresponde com a realidade midiática brasileira que convive com a concentração de vários veículos impressos, audiovisuais e virtuais em nome de restritos grupos familiares e comerciais, consolidando o monopólio e a propriedade cruzada. Traços desta assertiva podem ser verificados após levantamento quantitativo feito com as principais famílias midiáticas do estado paranaense:

\begin{tabular}{|c|c|c|c|}
\hline $\begin{array}{c}\text { Nome } \\
\text { familiar }\end{array}$ & $\begin{array}{c}\text { Grupo } \\
\text { pertencente }\end{array}$ & $\begin{array}{l}\text { Afiliação } \\
\text { TV }\end{array}$ & Município das suas emissoras \\
\hline Martinez & $\begin{array}{l}\text { Organização } \\
\text { OEME }\end{array}$ & CNT & Londrina e Curitiba \\
\hline Solano & Solano & Rede Vida & Corbélia e Toledo \\
\hline Petrelli & RIC & RECORD & $\begin{array}{c}\text { Toledo, Cascavel, Foz do Iguaçu, } \\
\text { Cornélio Procópio, Curitiba e } \\
\text { Maringá }\end{array}$ \\
\hline Massa & Massa & SBT & $\begin{array}{l}\text { Curitiba, Foz do Iguaçu, Ponta } \\
\text { Grossa, Apucarana, Londrina, S. } \\
\text { José dos Pinhais e Campo Largo }\end{array}$ \\
\hline Maluceli & J. Malucelli & BAND & $\begin{array}{c}\text { Maringá, Curitiba, Paranaguá e } \\
\text { Piraquara }\end{array}$ \\
\hline $\begin{array}{l}\text { Andrade } \\
\text { Vieira }\end{array}$ & $\begin{array}{l}\text { Andrade } \\
\text { Vieira }\end{array}$ & - & Londrina \\
\hline Lemanski & GRPCOM & GLOBO & $\begin{array}{l}\text { Curitiba, Londrina, Piraquara, } \\
\text { Maringá, Ponta Grossa, Foz do } \\
\text { Iguaçu, Paranavaí, Cascavel }\end{array}$ \\
\hline Tezelli & Tezelli & - & $\begin{array}{l}\text { Campo Mourão, Cianorte, } \\
\text { Guarapuava, Paranacity, Goioerê, } \\
\text { Telêmaco Borba e Brasilândia Sul }\end{array}$ \\
\hline Seleski & Seleski & - & $\begin{array}{c}\text { Marmeleiro, Francisco Beltrão, } \\
\text { Tapejara do Oeste, Realeza e São } \\
\text { João }\end{array}$ \\
\hline Mussi & Mussi & Mercosul & $\begin{array}{l}\text { Astorga, Guaíra, Curitiba, Campo } \\
\text { Largo, Icaraíma }\end{array}$ \\
\hline Muffato & TAROBA & BAND & Cascavel e Londrina \\
\hline Balbinotti & Balbinotti & - & $\begin{array}{l}\text { Barbosa Ferraz, Eng. Beltrão, São } \\
\text { João do Ivaí e Sarandi }\end{array}$ \\
\hline
\end{tabular}

Tabela 5: Dados das principais famílias proprietárias, Brasil (1967, Art.12) 


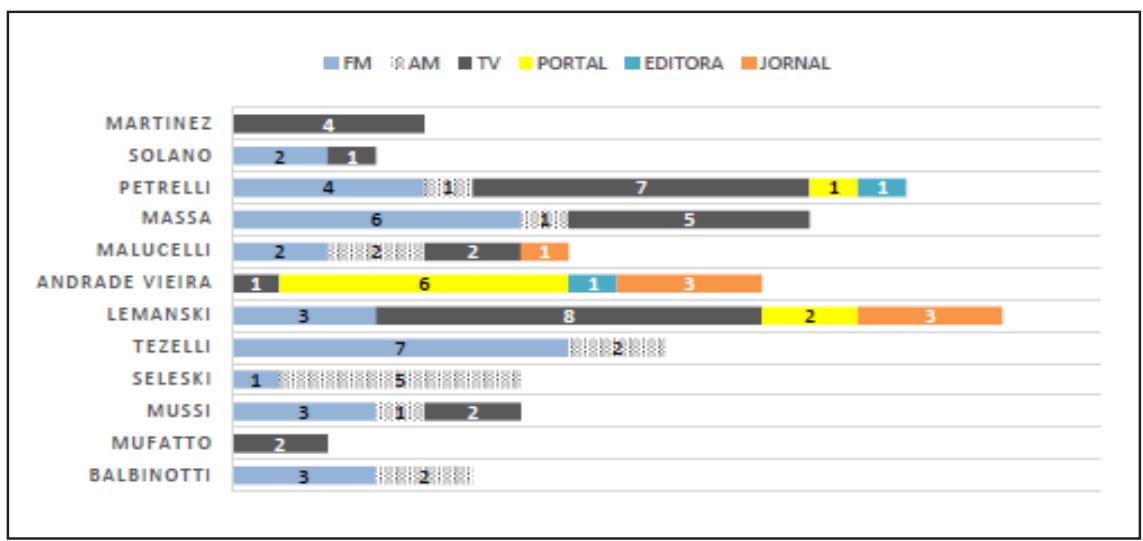

Gráfico 3: Levantamento quantitativo de veículos de comunicação de propriedade de famílias paranaenses, Görgen (op. cit.), Ministério das Comunicações (2015) e sites das emissoras dos grupos.

\begin{tabular}{|c|c|c|c|c|c|c|c|}
\hline Nome familiar & AM & FM & TV & Nome familiar & AM & FM & TV \\
\hline Martinez & - & - & +2 & Lemanski & - & - & +6 \\
\hline Solano & - & - & & Tezelli & - & +1 & - \\
\hline Petrelli & - & - & +5 & Seleski & +3 & - & - \\
\hline Massa & - & - & +3 & Mussi & - & - & - \\
\hline Maluceli & - & - & - & Muffato & - & - & - \\
\hline Andrade Vieira & - & - & - & Balbinotti & - & - & - \\
\hline
\end{tabular}

Tabela 6: Quantidade excedentes de veículos midiáticos por família conforme amparo legal ${ }^{8}$, Brasil (1967, Art.12).

Analisando as tabelas e gráfico deste item 3, podem-se inferir alguns pontos importantes no contexto midiático contemporâneo: 1) O mercado radiofônico paranaense é uma réplica do seu análogo nacional no tocante à propriedade das emissoras de sons e imagens. Metade das principais famílias estaduais excedem os limites legais de concessão radiofônicas. Cabe ressaltar que somente foram quantificadas as emissoras que realmente são de posse daquelas famílias, desconside-

\footnotetext{
${ }^{13}$ Art. 12 do Decreto-lei no 236, de 28 de fevereiro de 1967. Dispositivo legal que limita a propriedade cruzada em todo o país.
} 
rando as que estão em nome de terceiros, mesmo sabendo, segundo o domínio público, que são de propriedade de integrantes das famílias pesquisadas. 2) outro aspecto importante é a extemporaneidade da legislação radiofônica. Algumas organizações midiáticas detêm, além de emissoras de rádio e TV, mídias impressas e virtuais, consolidando uma homogeneização da informação em diversas plataformas, uma redução de vozes e de discursos díspares e uma falta de proteção ao mercado. Os meios comunicacionais mais recentes (impressos e digitais) não encontram sua regulação em nenhum arcabouço jurídico nem há agências que fiscalizem e normatizem os seus conteúdos e protejam os produtores de conteúdo e seus leitores, corroborando com o anacronismo legal do campo radiofônico. 3) seguindo no diapasão do item (2), o critério utilizado na limitação de concessão ou permissão para executar serviço de radiodifusão é a restrição quantitativa (tabela 4), diferentemente do utilizado em diversos países europeus, sul-americanos e norte-americanos, que é o índice de audiência.

\section{Considerações finais}

Cabe futuramente uma análise aprofundada da melhor opção para o modelo brasileiro. Limitar pela audiência pode incorrer na proteção de uma sociedade de ser alvo de uma influência integral ideológica ou discursiva de qualquer natureza, concebendo opção ao dialogismo, além de proteger o ambiente democrático. Exemplificando este argumento, verificou-se, em levantamento feito por este autor que tomou por base a lista de sócio e diretores de entidades radiofônicas comerciais fornecidos pelo Ministério das Comunicações (MINISTÉRIO DAS COMUNICAÇÕES, 2015), que em algumas pequenas cidades paranaenses (São João do Ivaí, Palotina, Nova Aurora, Ivaiporã, Dois Vizinhos e Arapongas) o mesmo sobrenome é sócio ou diretor de todas as rádios $\mathrm{AM} / \mathrm{FM}$ da cidade, contribuindo para a massificação do discurso e para a difusão maniqueísta da informação.

Pode-se constatar que o campo político-midiático brasileiro é estruturado, configurado e caracterizado em seu espectro global pelos velhos predicados do tempo das capitanias que, por conseguinte, coadunaram para o surgimento do protagonista deste setorial - o coronel e sua dilação conceitual (o coronel eletrônico). A legislação magna da área da radiodifusão (CBT) foi promulgada na sua íntegra 
à época, graças à pressão destes coronéis que, logo em seguida, fundaram uma instituição privada (ABERT), que é responsável, desde a década de 60, pelos interesses dos monopólios familiares da atualidade, pela manutenção do extemporâneo CBT e pelo soterramento monofônico da notícia.

O embricamento de interesses, a busca por novas audiências, a demanda pela inserção em novos mercados, a propriedade cruzada e a evolução das convergências das mídias fazem como que os protagonistas deste campo mantenham as mesmas práticas ilegais (ou pouco transparentes), amparados pela falta ou por uma frouxa fiscalização dos poderes executivo e legislativo, priorizando o privado e o econômico em detrimento ao público e cultural.

Desta forma, nota-se que ao manter o status quo do campo político-midiático presente, as relações de poder cidadão-mídia continuarão tendendo para uma menor polifonia e uma sociedade menos plural e diversificada.

\section{REFERENCIAS}

ABERT. Associação Brasileira de Emissoras de Rádio e TV. Disponível em: <http://www.abert.org.br/web/index.php/quemsomos/historiaabert $>$. Acesso em: 22 jun. 2015.

BACHTÖLD, Felipe. Congressistas eleitos têm 55 concessões. Jornal Folha de S.Paulo, 2014. Disponível em: <http://www1.folha.uol.com.br/ poder/2014/12/1561839-congressistas-eleitos-tem-55-concessoes.shtml>. Acesso em: 22 jul. 2015

BELLINTANI, Adriana. Conspiração contra o Estado Novo. Porto Alegre: EDIPUCRS, 2002.

BRASIL. Presidência da República. Decreto-lei no 236, de 28 de fevereiro de 1967. Dispõe sobre a complementação e a modificação da lei ${ }^{\circ}$ 4117, de 27 de agosto de 1962 [CBT]. Diário Oficial da União, de 28 de fevereiro de 1967. Brasília, 1967.

\section{. Congresso. Senado. Constituição da República Federativa do}


Brasil, de 5 de outubro de 1988. Diário Oficial da República Federativa do Brasil, no 191-A. Brasília, 1988.

CARONE, Edgar. Coronelismo: definição histórica e bibliográfica. Revista de Administração de Emprêsas, Rio de Janeiro, v.11, n. 3, 1971, p.85-92.

CARVALHO, José Murilo. Mandonismo, Coronelismo, Clientelismo: uma discussão conceitual, In: Pontos bordados: escritos de história e política. Belo Horizonte: UFMG, 2005.

CORTÉS, Carlos. Política gaúcha (1930-1964). Porto Alegre: EDIPUCRS, 2007.

DIAP (Departamento Intersindical de Assessoria Parlamentar). Radiografia do novo Congresso: legislatura 2015-2019. Brasília/DF, 2014.

FAORO, Raymundo. Os Donos do Poder - formação do patronato político brasileiro. Porto Alegre, Editora Globo, 1958

GÖRGEN, James. Donos da mídia. Disponível em: <http:// donosdamidia.com.br>. Acesso em: 3 abr. 2015.

LEAL, Victor Nunes. Coronelismo, enxada e voto: o município e o regime representativo no Brasil. Rio de Janeiro: Nova Fronteira, 1997.

LIMA, Venício. Mídia: crise política e poder no Brasil. São Paulo: Perseu Abramo, 2006.

Os interesses explicitados. Observatório da Imprensa, 2011a. Disponível em:<http://observatoriodaimprensa.com.br/interesse-publico/ os-interesses-explicitados/>. Acesso em: 2 jun. 2015.

Marco regulatório da comunicação: ainda a propriedade cruzada. Revista Carta Maior,2011b. Disponível em: <http://cartamaior.com. $\mathrm{br} /$ ?/Coluna/Marco-regulatorio-da-comunicacao-ainda-a-propriedadecruzada/22189>. Acesso em: 19 jun. 2015.

Governo admite propriedade cruzada. Observatório da 
Imprensa, 2011c. Disponível em: < http://observatoriodaimprensa.com. br/interesse-publico/governo-admite-propriedade-cruzada/>. Acesso em: 3 mai.2015.

. Mídia: teoria e política. São Paulo: Perseu Abramo, 2012.

MINISTÉRIO DAS COMUNICAÇÕES. Espaço do radiodifusor: radiodifusão comercial. Disponível em: http://www.comunicacoes.gov.br/ espaco-do-radiodifusor/radiodifusao-comercial. Acesso em 2 ago. 2015.

PIERANTI, Octávio. Debate em Audiência Pública na CCTCI sobre o Projeto de Lei $\mathbf{n}^{\circ} \mathbf{4 . 0 2 6}$, de 2004, sobre os limites à concentração econômica nos meios de comunicação social, 2015.Disponível em: $<$ http://www2.camara.leg.br/atividade-legislativa/comissoes/ comissoes-permanentes/cctci/audiencias-publicas/2015/2015-06-11-appl-4026-de-2004-meios-de- comunicacao-social/octavio-penna-pierantiministerio-das-comunicacoes>. Acesso em: 23 jun. 2015.

QUERINO, Ana Carolina. Os limites da propriedade cruzada. Observatório da Imprensa, 2001. Disponível em: <http://www. observatoriodaimprensa.com.br/artigos/ipub180720012.htm>. Acesso em: 2 mai.2015.

SANTOS, Suzy. Relações incestuosas: mercado global, empresariado nacional de radiodifusão e líderes políticos/regionais. In: XXXI CONGRESSO BRASILEIRO DE ESTUDOS INTERDISCIPLINARES DE COMUNICAÇÃO, Natal, 2008. Anais do VIII Encontro dos Núcleos de Pesquisa em Comunicação - NP Políticas e Estratégias de Comunicação, 2008a, p.1-16.

Os prazos de validade do coronelismo: transição no coronelismo e no coronelismo eletrônico. In: SARAIVA, E; MARTINS, P.E., PIERANTI, O (org.). Democracia e regulação dos meios de massa. Rio de Janeiro: Fundação Getúlio Vargas, 2008b, v2.1, p.223-241.

SANTOS, Suzy; CAPPARELLI, Sérgio. Coronelismo, radiodifusão e voto: a nova face de um conceito. In: BRITTOS, Valério; BOLAÑO, César (org.). Rede Globo: 40 anos de poder e hegemonia. São Paulo: Paulus, 2005, p. 77-101. 
SCHWARTZMAN, Simon. Bases do autoritarismo brasileiro. Rio de Janeiro: Campus, 1982.

WEBER, Max. Economia e sociedade: fundamentos da sociologia compreensiva. Vol. 1, Trad. Regis Barbosa e Karen Elsabe Barbosa. Brasília: Editora UNB, 1994 
AÇÃO MIDIÁTICA, n.11. Jan/jun. 2016. Curitiba. PPGCOM-UFPR. ISSN 2238-0701

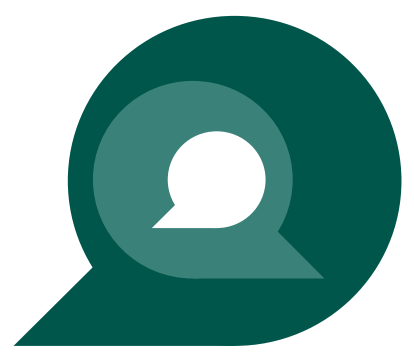

